\title{
The effects of glomerular and tubular renal progenitors and derived extracellular vesicles on recovery from acute kidney injury
}

Andrea Ranghino ${ }^{1 *}$, Stefania Bruno ${ }^{2}$, Benedetta Bussolati ${ }^{2}$, Aldo Moggio², Veronica Dimuccio², Marta Tapparo ${ }^{1}$, Luigi Biancone', Paolo Gontero ${ }^{3}$, Bruno Frea ${ }^{3}$ and Giovanni Camussi ${ }^{1}$

\begin{abstract}
Background: Mesenchymal stromal cells (MSCs) and renal stem/progenitors improve the recovery of acute kidney injury (AKI) mainly through the release of paracrine mediators including the extracellular vesicles (EVs). Several studies have reported the existence of a resident population of MSCs within the glomeruli (GI-MSCs). However, their contribution towards kidney repair still remains to be elucidated. The aim of the present study was to evaluate whether GI-MSCs and GI-MSC-EVs promote the recovery of AKI induced by ischemia-reperfusion injury (IRI) in SCID mice. Moreover, the effects of GI-MSCs and GI-MSC-EVs were compared with those of $\mathrm{CD}_{133^{+}}$progenitor cells isolated from human tubules of the renal cortical tissue $\left(T-C D 133^{+}\right.$cells) and their EVs (T-CD133+-EVs).

Methods: IRI was performed in mice by clamping the left renal pedicle for 35 minutes together with a right nephrectomy. Immediately after reperfusion, the animals were divided in different groups to be treated with: GI-MSCs, T-CD $133^{+}$cells, GI-MSC-EVs, T-CD133-EVs or vehicle. To assess the role of vesicular RNA, EVs were either isolated by floating to avoid contamination of non-vesicles-associated RNA or treated with a high dose of RNase. Mice were sacrificed 48 hours after surgery.

Results: GI-MSCs, and GI-MSC-EVs both ameliorate kidney function and reduce the ischemic damage post IRI by activating tubular epithelial cell proliferation. Furthermore, $\mathrm{T}-\mathrm{CD} 133^{+}$cells, but not their EVs, also significantly contributed to the renal recovery after IRI compared to the controls. Floating EVs were effective while RNase-inactivated EVs were ineffective. Analysis of the EV miRnome revealed that GI-MSC-EVs selectively expressed a group of miRNAs, compared to EVs derived from fibroblasts, which were biologically ineffective in IRI.

Conclusions: In this study, we demonstrate that GI-MSCs may contribute in the recovery of mice with AKI induced by IRI primarily through the release of EVs.
\end{abstract}

Keywords: Glomerular mesenchymal stromal cells, Extracellular vesicles, Ischemia-reperfusion injury, Renal regeneration

\footnotetext{
*Correspondence: andrea.ranghino@unito.it

'Department of Medical Sciences and Molecular Biotechnology Center,

University of Torino, Corso Dogliotti 14, Torino 10126, Italy

Full list of author information is available at the end of the article
} 


\section{Background}

Acute kidney injury (AKI) is a major clinical disorder that affects more than $20 \%$ of hospitalized patients. Furthermore, the adjusted odds ratio for hospital mortality in patients that develop AKI stands at 4:1 [1,2]. Out of all the causes of AKI, ischemia-reperfusion injury (IRI) signifies to be one of the most important, as it is characterized by severe tubular damage associated with rapid worsening of the renal function [3]. Moreover, IRI may subsequently develop into chronic kidney disease (CKD), mainly due to fibroblast proliferation and the deposition of extracellular matrix.

Regeneration of injured tubular and endothelial cells after AKI may occur through multiple mechanisms including the de-differentiation of surviving resident cells [4-8] and/or the intrinsic ability of resident progenitor cells to proliferate and differentiate into new renal cells [9-14]. A population of resident renal progenitor cells expressing the human stem cell antigen CD133 and the embryonic renal marker PAX2 has been identified in the tubular compartment [9]. Furthermore, Sagrinati et al. reported the presence of renal progenitor cells characterized by the co-expression of CD133 and CD24 within the Bowman's capsule [11]. Subsequently, $\mathrm{CD}_{133^{+}}$progenitor cells were also found to be present in different compartments of the nephron $[9,11-13,15]$. Several authors demonstrated that these progenitor cells could contribute towards kidney repair after injury in different murine models of AKI $[9,10,12,16]$. In addition, over the last decade, numerous studies performed in animal models of AKI and CKD have reported the beneficial effects of mesenchymal stromal cells (MSCs) not only in the recovery of renal function after IRI, but also in reducing the progression of the chronic damage that followed [17-23]. The mechanism by which MSCs exert these effects seems to be primarily due to a paracrine action on the target cells rather than transdifferentiation into resident cells [24-27]. It is well known that MSCs release soluble factors which promote the recovery of damaged renal cells [28-31]. Among these factors, extracellular vesicles (EVs) have been implicated to play a role in the paracrine actions of MSCs [32]. EVs are circular cellular membrane fragments that are released from a given cell type and influence target cells by delivering proteins, lipids and nucleic acids [33-37]. Amidst various types of nucleic acids transported by EVs, the capacity of mRNAs to induce epigenetic changes in target cells in murine models of AKI using MSC-derived EVs has been well demonstrated by several authors [38-40]. In addition, several studies have also demonstrated the presence of microRNAs (miRNA) in EVs that could be transferred to the target cells modulating their phenotype $[36,41]$. Other than nucleic acids, proteins carried by EVs also have significant effects on target cells. For instance, Sallustio et al. recently reported that the protein decorin carried by EVs from adult renal stem/progenitor cells improved the survival of tubular epithelial cells in an in vitro toxic AKI model [42].

MSCs are stem cells that have been reported to reside in almost all organs. Furthermore, they have also been identified to be present within the glomeruli of both mice and human $[43,44]$. However, their role in the repair of kidney injury is still unknown.

The aim of the present study was to evaluate whether the MSCs derived from human glomeruli (Gl-MSCs) and their EVs (Gl-MSC-EVs) promote the recovery of AKI induced by IRI in SCID mice. Furthermore, the effects of Gl-MSCs and Gl-MSC-EVs were compared with those of $\mathrm{CD}_{133^{+}}$progenitor cells isolated from human tubules of the renal cortical tissue ( $\mathrm{T}-\mathrm{CD} 133^{+}$cells) and their EVs (T-CD133+-EVs).

\section{Methods \\ Isolation and characterization of different resident renal stem/progenitor cell populations}

Normal portions of renal cortex were obtained from surgically removed kidneys of cancer patients with informed consent, obtained in accordance with the Declaration of Helsinki and after approval by the ethic committee of the Azienda Ospedaliera Universitaria, Città della Salute e della Scienza, Torino (N. 168/2014). After dissection and passage through a graded series of mesh (60 and 120 mesh per inch), $\mathrm{T}-\mathrm{CD} 133^{+}$cells were isolated form the tubular fraction by magnetic cell sorting, using the MACS system (Miltenyi Biotec, Auburn, AL, USA). T$\mathrm{CD}_{133^{+}}$cells were cultured and expanded as previously described [9]. The glomeruli were recovered from the top of the 120-mesh sieve and collected at the bottom of a conical tube by low-speed centrifugation $(300 \mathrm{~g}, 5 \mathrm{mi}-$ nutes). To obtain Gl-MSCs, the visceral layer of the Bowman's capsule was removed mechanically by several rounds of aspirations/expulsions using a 10-ml pipette, followed by an enzyme digestion for 2 minutes with collagenase I (Sigma-Aldrich, St. Louis, MO. USA). The decapsulated glomeruli were then collected by low-speed centrifugation and transferred to a fibronectin-coated T25 flask and cultured as previously described [44].

Cytofluorimetric analyses were performed as previously described $[9,44]$ using the following antibodies: anti-CD105,-CD29,-CD73,-CD44,-CD133,-CD146, -CD24, -CD31, -CD90, -CD45 (all from Mitenyi Biotech, Auburn, AL, USA). T-CD133 ${ }^{+}$cells co-expressed CD73, CD44, CD29, CD90, CD146 and CD24; no expression of CD45, CD31 and CD105 was detected (Table 1). Gl-MSCs were positive for surface markers characteristic of MSCs, such as CD29, CD73, CD105, CD146, CD44, CD90 and for CD24. Gl-MSCs were negative 
Table 1 Phenotype of different renal stem/progenitor cell populations

\begin{tabular}{llll}
\hline & T-CD133+ & Gl-MSCs & Fibroblasts \\
\hline Positive & CD90 CD73 CD44 CD29 CD24 CD133 CD146 & CD90 CD73 CD44 CD29 CD24 CD105 CD146 & CD73 CD44 CD29 CD24 \\
Negative & CD45 CD31 CD105 & CD45 CD31 CD133 & CD45 CD133 CD90 CD31 CD146 CD105
\end{tabular}

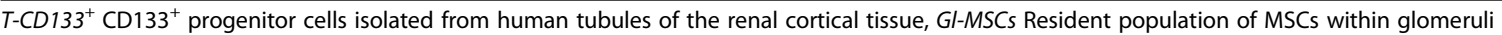

for CD133 and for specific hematopoietic (CD45) and endothelial markers (CD31) (Table 1). Human dermal fibroblasts were used as control (Lonza, Basel, Switzerland). FACS analyses indicated that the fibroblasts expressed CD73, CD44, CD29 and CD24 (Table 1).

\section{Isolation and characterization of EVs derived from Gl-MSCs and $\mathrm{T}-\mathrm{CD} 133^{+}$cells}

Briefly, healthy stem/progenitor cells were incubated in serum-free RPMI 1640 overnight at $37{ }^{\circ} \mathrm{C}$. Post incubation, the cell supernatant was collected and centrifuged at $3,000 \mathrm{~g}$ for 20 minutes to remove cell debris and apoptotic bodies. This was followed by ultracentrifugation at 100,000 g for 2 hours at $4{ }^{\circ} \mathrm{C}$ (Beckman Coulter Optima L-90 K, Fullerton, CA, USA) to pellet the EVs $[38,45]$. The EVs obtained were then resuspended in RPMI containing 1\% dimethyl sulfoxide (DMSO, SigmaAldrich) and stored at $-80{ }^{\circ} \mathrm{C}$ until further use.

In order to trace EVs by fluorescent microscopy post in vivo injection, they were labelled with PKH26 dye (a red fluorescent aliphatic cromophore intercalating into lipid bilayers) as per manufacturer's instructions (PKH26 dye, Sigma-Aldrich). After labelling, the EVs were washed with PBS by ultracentrifugation at 100,000 g for 2 hours at $4{ }^{\circ} \mathrm{C}$.

To separate membrane-enclosed vesicles from aggregates of protein and other molecules (e.g. extra-vesicle RNAs), EVs were isolated by a floating process into a gradient, as described previously [46, 47]. Briefly, EVs from 80 million Gl-MSCs were resuspended in $1.35 \mathrm{ml}$ of buffer $(0.25 \mathrm{M}$ sucrose, $10 \mathrm{mM}$ Tris $\mathrm{pH} 8$ and $1 \mathrm{mM}$ EDTA), transferred to a SW55Ti rotor tube (Beckman Coulter) and mixed with $60 \%$ stock solution of Optiprep (Sigma-Aldrich) in a 1:1 ratio. Next, $1.2 \mathrm{ml}$ of $20 \%$ Optiprep solution was layered on top, followed by $1.1 \mathrm{ml}$ of $10 \%$ Optiprep solution. The tubes were then ultracentrifuged at $350,000 \mathrm{~g}$ for 1 hour at $4{ }^{\circ} \mathrm{C}$. Five fractions of $1 \mathrm{ml}$ were collected from the top of the tubes, each fraction was diluted in $20 \mathrm{ml}$ PBS and ultracentrifuged at $100,000 \mathrm{~g}$ for 1 hour at $4{ }^{\circ} \mathrm{C}$ to pellet the EVs. Nanosight analyses (not shown) indicated that fraction 2 contained vesicles with a similar size range of exosomes, and therefore that fraction was used for the in vivo experiments. Treatment with $0.2 \mu \mathrm{g} / \mathrm{mL}$ RNase did not inactivate RNA present in the floating fraction $(0.9 \mathrm{ng} / \mathrm{mL}$ untreated; $1.0 \mathrm{ng} / \mathrm{mL}$ RNase floating EVs).
To characterize the phenotype of EVs, cytofluorimetric analysis was performed as previously described [45]. Briefly, EVs were incubated for 15 minutes at $4{ }^{\circ} \mathrm{C}$ with the following antibodies: anti-CD24,-CD29,-CD146, -CD133 (Miltenyi Biotech), -CD107, (Becton Dickinson, Franklin Lakes, NJ, USA) and SSEA4 (R\&D Systems, Minneapolis, MN, USA). Mouse nonimmune isotypic IgG (Miltenyi Biotech) was used as control. For each preparation of EVs, 5000 particles were acquired using the Guava easyCyte ${ }^{\mathrm{Tu}}$ Flow Cytometer (EMD Millipore, Billerica, MA, USA) and analysed with the InCyte ${ }^{\text {ta }}$ software.

EV size and concentration were measured by the NanoSight LM10 instrument (NanoSight Ltd, Amesbury, UK) equipped with a $405 \mathrm{~nm}$ laser and the nanoparticle tracking analyses (NTA) software version 2.3. Three videos of 30 seconds duration were recorded in order to perform the analyses.

\section{RNase treatment, RNA isolation and analyses}

For selected experiments, EVs were treated with $5 \mu \mathrm{g} / \mathrm{ml}$ of RNase for 1 hour at $37{ }^{\circ} \mathrm{C}$. The reaction was stopped by adding $1 \mathrm{U}$ of RNase inhibitor (Ambion, Austin, TX, USA) per $5 \mathrm{ng}$ of RNAse used, and the EVs washed and pelleted by ultracentrifugation ( 2 hours at 100,000 g). RNA was extracted from cells and EVs using the mirVana RNA isolation kit (Applied Biosystems, Foster City, CA, USA) as per the manufacturer's protocol. The quantification of RNA was performed using the Nanodrop spectrophotometer (ND-1000; Nanodrop, Wilmington, DE, USA), and the quality of RNA was assessed by capillary electrophoresis on an Agilent 2100 Bioanalyzer (Agilent Technologies, Santa Clara, CA, USA) using the Total Eukaryotic Pico RNA kit.

\section{miRNA expression and target gene enrichment analysis}

To investigate miRNAs carried by Gl-MSC-EVs and fibroblast EVs, 60 ng of input RNA was run on TaqMan ${ }^{\text {tw }}$ Array Human MicroRNA A card (Thermo Fisher Scientific, Waltham, MA, USA), that profiles 365 human mature miRNAs by qRT-PCR. Raw Ct values were analysed using the SDS 2.3 software with automatic baseline and threshold settings. The data were expressed as Relative Quantification (RQ) using the $\Delta \Delta \mathrm{Ct}$ method and RNU6B was used as housekeeping gene for normalization. To identify miRNA specifically expressed and upregulated in Gl- 
MSC-EVs, we applied different Ct cutoff levels for fibroblast EVs (Ct $>35$, not expressed) and Gl-MSC-EVs (Ct $<35$, expressed). Target prediction and biological process enrichment analysis was conducted using Funrich V3 analysis tool [48]. Only the biological process of target genes with a $p$ value $<0.05$ were considered as significantly enriched.

\section{Animal model of monolateral kidney IRI}

All procedures were approved by the Ethics Committee of the University of Torino and conducted in accordance with the National Institute of Health Guide for the Care and Use of Laboratory Animals. Male SCID mice (Charles River Laboratories, Wilmington, MA, USA) aged 7 to 8 weeks and weighing 22 to 26 g were anesthetized with an intramuscular (i.m.) injection of zolazepam $80 \mathrm{mg} / \mathrm{kg}$ and xilazina $16 \mathrm{mg} / \mathrm{kg}$. Postoperatively, the animals were closely monitored, and ketorolac $(5 \mathrm{mg} / \mathrm{kg}$ ) was administered as an analgesic if required. Under sterile conditions, a small mid laparotomy was made, the left kidney exposed and the renal pedicle was clamped for 35 minutes using a nontraumatic vascular clamp (Fine Science Tools, Foster City, CA, USA). Immediately after clamping the left renal pedicle, a right nephrectomy was performed using a subcapsular technique. Briefly, after isolation and ligation of the right kidney pedicle, the renal capsule was dissected and the renal parenchyma exposed. The nephrectomy was performed by the incision of the renal parenchyma leaving the capsule in situ. This procedure allows an accurate hemostasis to exclude bleeding due to the failure of the ligation of the renal pedicle. The laparotomy incision was temporarily closed during ischemia and the body temperature was maintained at $37{ }^{\circ} \mathrm{C}$ during the surgical intervention by placing the animals on a heating plate. Reperfusion of the kidney was then confirmed visually after removing the clamp. The abdominal incision was closed with a 6-0 silk suture. After surgical intervention, the mortality rate was approximately $10 \%$.

In order to evaluate the effects of cells or EVs in AKI-IRI mice, the animals were divided in ten groups based on the different treatments (Table 2). The dose of EVs used was selected as the number of EVs produced overnight by $1 \times 10^{5}$ cells under serum starvation (T-CD $133^{+}$-EVs: $480 \times 10^{6} /$ mouse; Gl-MSC-EVs: $400 \times 10^{6} /$ mouse; Gl-MSC-EV-float: $400 \times 10^{6} /$ mouse; F-EVs: $230 \times 10^{6} /$ mouse). For all the experiments, cells cultured up to passage 6 were detached by trypsin (Sigma-Aldrich), washed and resuspended in PBS (Lonza). The cells were injected intravenously $(120 \mu \mathrm{l}$ injecting volume, i.v.) through the tail vein. All the animals were sacrificed at day 2 after surgery. For bio-distribution analysis, mice were sacrificed at 1,6 and 24 hours after surgery.

In order to evaluate the long-term effect of Gl-MSCs and $\mathrm{T}-\mathrm{CD} 133^{+}$cells on kidney function post IRI, and also to check the potential development of malignancy, supplementary experiments were performed in mice. The animals were divided into four groups according to the treatment administered intravenously immediately after surgery: normal mice $(n=5)$; IRI-CTL mice $(n=6)$ injected with vehicle alone; IRI-Gl-MSC mice $(\mathrm{n}=6)$ injected with

Table 2 Schematic representation of the groups of mice used in the study

\begin{tabular}{|c|c|c|c|c|}
\hline & Treatment & Doses & No. animals & Time of sacrifice \\
\hline & \multirow[t]{2}{*}{ Normal } & - & 5 & $48 \mathrm{~h}$ \\
\hline & & - & 5 & 3 weeks \\
\hline & Sham-operated & - & 5 & $48 \mathrm{~h}$ \\
\hline & \multirow[t]{2}{*}{ IRI-CTL (vehicle) } & - & 8 & $48 \mathrm{~h}$ \\
\hline & & - & 6 & 3 weeks \\
\hline \multirow[t]{4}{*}{ Cells } & \multirow[t]{2}{*}{ IRI-GI-MSC } & $10^{5}$ cells & 8 & $48 \mathrm{~h}$ \\
\hline & & $10^{5}$ cells & 6 & 3 weeks \\
\hline & \multirow[t]{2}{*}{ IRI-T-CD $133^{+}$} & $10^{5}$ cells & 8 & $48 \mathrm{~h}$ \\
\hline & & $10^{5}$ cells & 6 & 3 weeks \\
\hline \multirow[t]{5}{*}{ EVs } & IRI-GI-MSC-EVs & $400 \times 10^{6} \mathrm{EVs}^{*}$ & 8 & $48 \mathrm{~h}$ \\
\hline & IRI-GI-MSC-EVs-float & $400 \times 10^{6} \mathrm{EVs}^{*}$ & 6 & $48 \mathrm{~h}$ \\
\hline & IRI-RNase-GI-MSC-EVs & $400 \times 10^{6} \mathrm{EVs}^{*}$ & 8 & $48 \mathrm{~h}$ \\
\hline & IRI-T-CD133+-EVs & $480 \times 10^{6} \mathrm{EVs}^{*}$ & 8 & $48 \mathrm{~h}$ \\
\hline & $|R|-F-E V s$ & $230 \times 10^{6} \mathrm{EVs}^{*}$ & 5 & $48 \mathrm{~h}$ \\
\hline
\end{tabular}

IRI ischemia-reperfusion injury, CTL control, Gl-MSC glomerular mesenchymal stromal cells, T-CD133+-EVs T-CD133+-derived EVs, EVs extracellular vesicles, GI-MSC-EVs GI-MSC

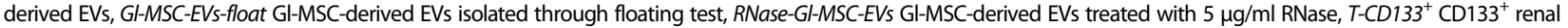
tubular cells, F-EVs fibroblast-derived EVs. ${ }^{*}$ The doses of EVs used were selected as the number of EVs produced overnight by $10^{5}$ cells in serum starvation 
$1 \times 10^{5}$ Gl-MSCs; IRI-T-CD133 ${ }^{+}$mice $(\mathrm{n}=6)$ injected with $1 \times 10^{5}$ T-CD133+ cells. The animals were sacrificed 3 weeks after intervention.

\section{Renal function}

Blood samples for the measurement of plasma creatinine and blood urea nitrogen (BUN) were collected at 2 days after IRI from the different AKI groups and at 3 weeks from the long-term four groups of mice. Creatinine concentrations were determined using a colorimetric microplate assay based on the Jaffe reaction (Quantichrome Creatinine Assay, BioAssay Systems, Hayward, CA, USA). Creatinine levels that exceeded $0.3 \mathrm{mg} / \mathrm{dl}$ were considered abnormal (normal range in our laboratory: 0.1 to $0.3 \mathrm{mg} / \mathrm{dl}$ ). BUN was measured by direct quantification of serum urea with a colorimetric assay kit according to the manufacturer's protocol (Arbor Assays, Ann Arbor, MI, USA).

\section{Morphological studies}

For renal histology, 5- $\mu$ m-thick paraffin-embedded kidney sections were routinely stained with hematoxylin and eosin (Merck, Darmstadt, Germany). To evaluate the score of the AKI, luminal hyaline casts and the cell lose (denudation of tubular basement membrane) were assessed in non-overlapping fields (up to 28 for each section) using a 440 objective (high power field, HPF). The number of casts and tubular profiles showing necrosis were recorded in a single-blind fashion [49].

Immunohistochemistry to detect the proliferation of tubular cells was performed by BrdU incorporation as previously described [38]. Kidney sections were subjected to antigen retrieval and stained with antiproliferating cell nuclear antigen (PCNA) (1:400, monoclonal anti-PCNA antibody; Santa Cruz Biotechnology, Dallas, TX, USA) or with anti-BrdU (1:200, Dako North America Inc., Carpinteria, CA, USA). Immunoperoxidase staining was performed using 1:300 dilution of anti-mouse horseradish peroxidase (HRP, Pierce, Rockford, IL, USA). Scoring for BrdU- and PCNA-positive cells was carried out by counting the number of positive nuclei per HPF $(\times 40)$ in ten randomly chosen sections of the kidney cortex.

Confocal microscopy analysis (Zeiss LSM 5 Pascal; Carl Zeiss International, Oberkochen, Germany) was performed on frozen sections to assess the localization of PKH26-labelled EVs in different organs as described previously [38]. Nuclei were stained with Hoechst 33258 dye (Sigma-Aldrich).

\section{Statistical analysis}

Statistical analysis was performed by using the $t$ tests, analysis of variance (ANOVA) with Newmann-Keuls' or ANOVA with Dunnett's multiple comparison tests as appropriate. A $p$ value of $<0.05$ was considered significant.

\section{Results}

GI-MSCs cells are more effective in promoting the recovery of AKI compared to $\mathrm{T}-\mathrm{CD} 133+$ cells

Forty-eight hours after the induction of IRI, serum creatinine and BUN markedly increased in IRI mice compared to healthy and sham-operated mice (Fig. 1). Furthermore,

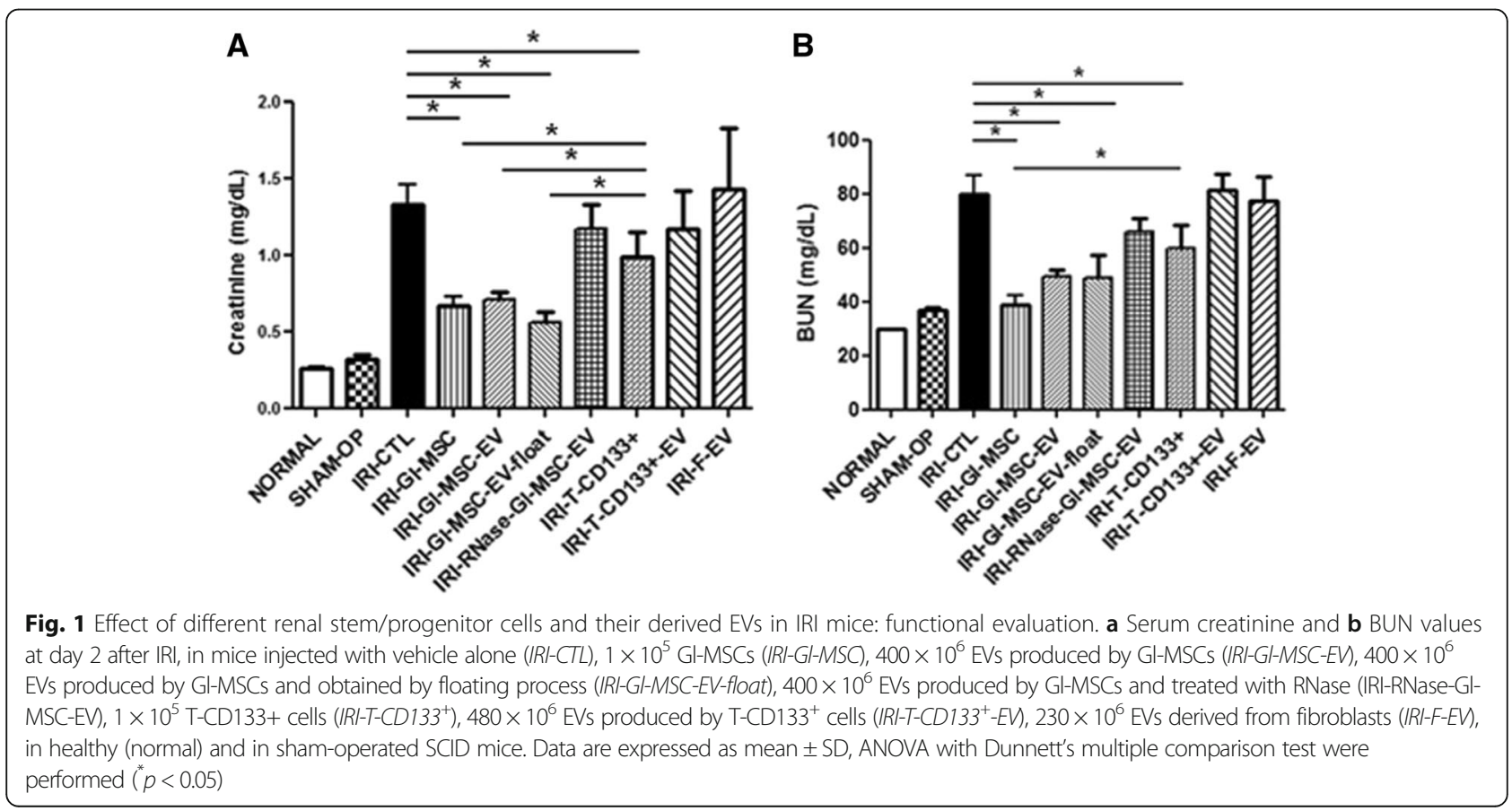


histological analysis of the kidney revealed severe tubular damage characterized by tubular necrosis and presence of proteinaceous casts inside the lumen of tubules in IRI mice (Fig. 2). However, injecting mice with Gl-MSCs significantly reduced both functional and histological alterations observed in IRI mice, evaluated 48 hours after surgery (Figs. 1 and 2). Although treating IRI mice with $\mathrm{T}-\mathrm{CD} 133^{+}$cells was associated with a significant improvement in renal function and morphology compared to control animals, the treatment was not as efficient in ameliorating the recovery after IRI as the treatment with Gl-MSCs cells. In addition, 48 hours after IRI induction, PCNA staining showed a significant increase in tubular cell proliferation in mice treated with Gl-MSCs compared to both control mice and mice treated with T-CD133 ${ }^{+}$cells (Fig. 3). No significant differences, however, were observed in the rate of apoptosis between animals treated with Gl-MSCs or T-CD133 ${ }^{+}$cells (data not shown).
In order to evaluate the long-term effects of Gl-MSCs and $\mathrm{T}-\mathrm{CD} 133^{+}$cells, mice were sacrificed 3 weeks after intervention. Analysis of the results revealed no significant differences in the functional and histological markers of tubular damage between the control group and the animals treated with cells (data not shown). In addition, no signs of neoplastic lesions or mal-differentiation of the engrafted cells were detected in the renal parenchyma (data not shown).

\section{Characterization of EVs derived from GI-MSCs and T-CD133 + cells}

Cytofluorimetric analyses of Gl-MSC-EVs showed the presence of several antigens expressed by Gl-MSCs (CD146, CD29 and CD24), as well as the exosomal marker CD107 (Fig. 4a). FACS analyses of T-CD133 ${ }^{+}$-EVs revealed the expression of typical $\mathrm{CD} 133^{+}$cells markers including CD24 and CD133. In addition, T-
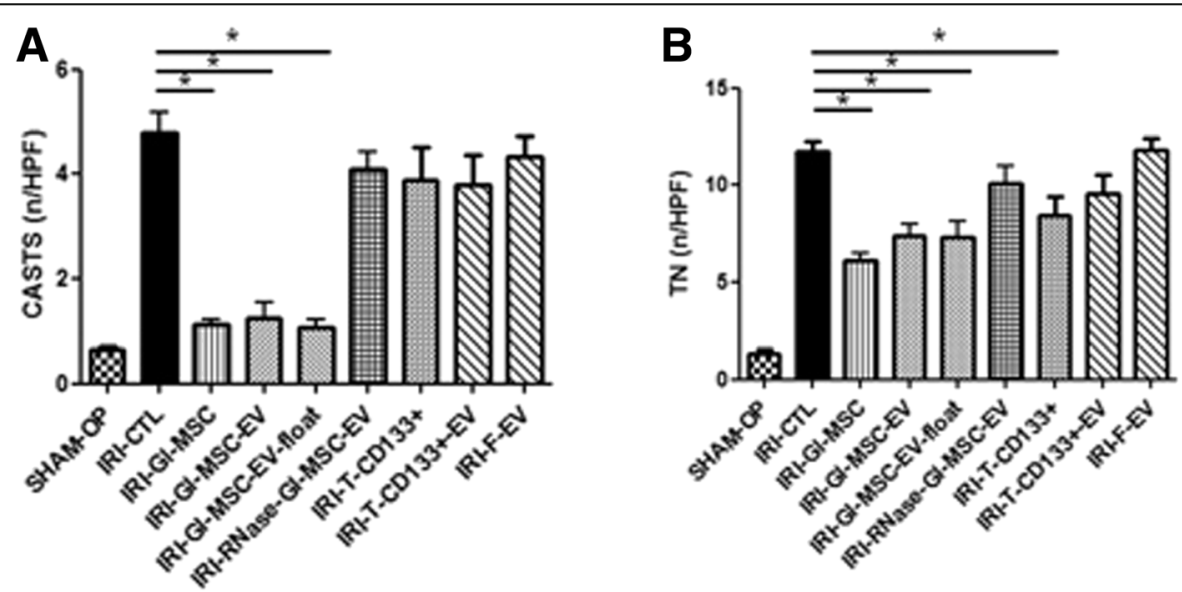

C

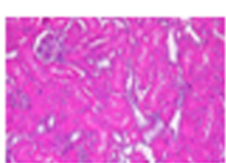

SHAM-OP

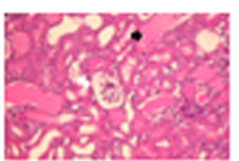

IRI-CTL

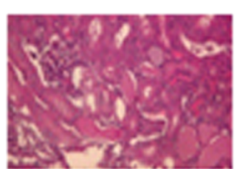

IRI-RNase-

GI-MSC-EV

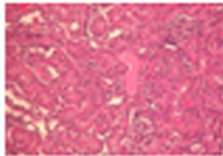

IRI-GI-MSC

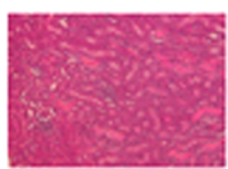

IRI-T-CD133
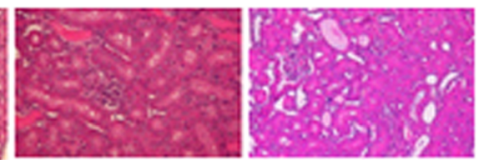

IRI-GI-MSC-EV IRI-GI-MSC-EV-float

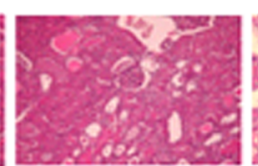

IRI-T-CD133*-EV

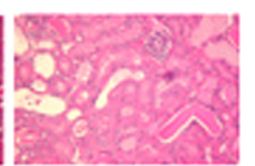

IRI-F-EV

Fig. 2 Effect of different renal stem/progenitor cells and their derived EVs in IRI mice: renal morphology. a The number of hyaline casts and b tubular necrosis (TN) observed under high power field (HPF: $\times 40)$ is expressed as mean \pm SD. An ANOVA with Dunnett's multiple comparison test was performed, $(*<0.05)$. c Representative micrographs of renal histology of: IRI mice injected with different treatments and sham-operated SCID mice. Original magnification: $\times 20$. In the representative image related to IRI-CTL intratubular hyaline cast (black arrow) and a tubule with signs of necrosis (epithelial cell denudation and presence of intratubular cell debris) (white arrow) can be observed. IRI-CTL mice injected with vehicle alone, IRI-GI-MSC mice injected with GI-MSC, IRI-GI-MSC-EV EVs produced by GI-MSCS, IRI-GI-MSC-EV-float EVs produced by GI-MSCs and obtained by floating

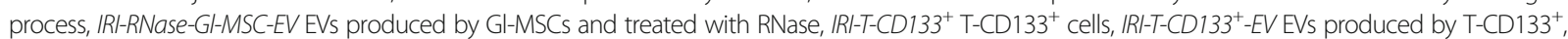
IRI-F-EV EVs derived from fibroblasts 


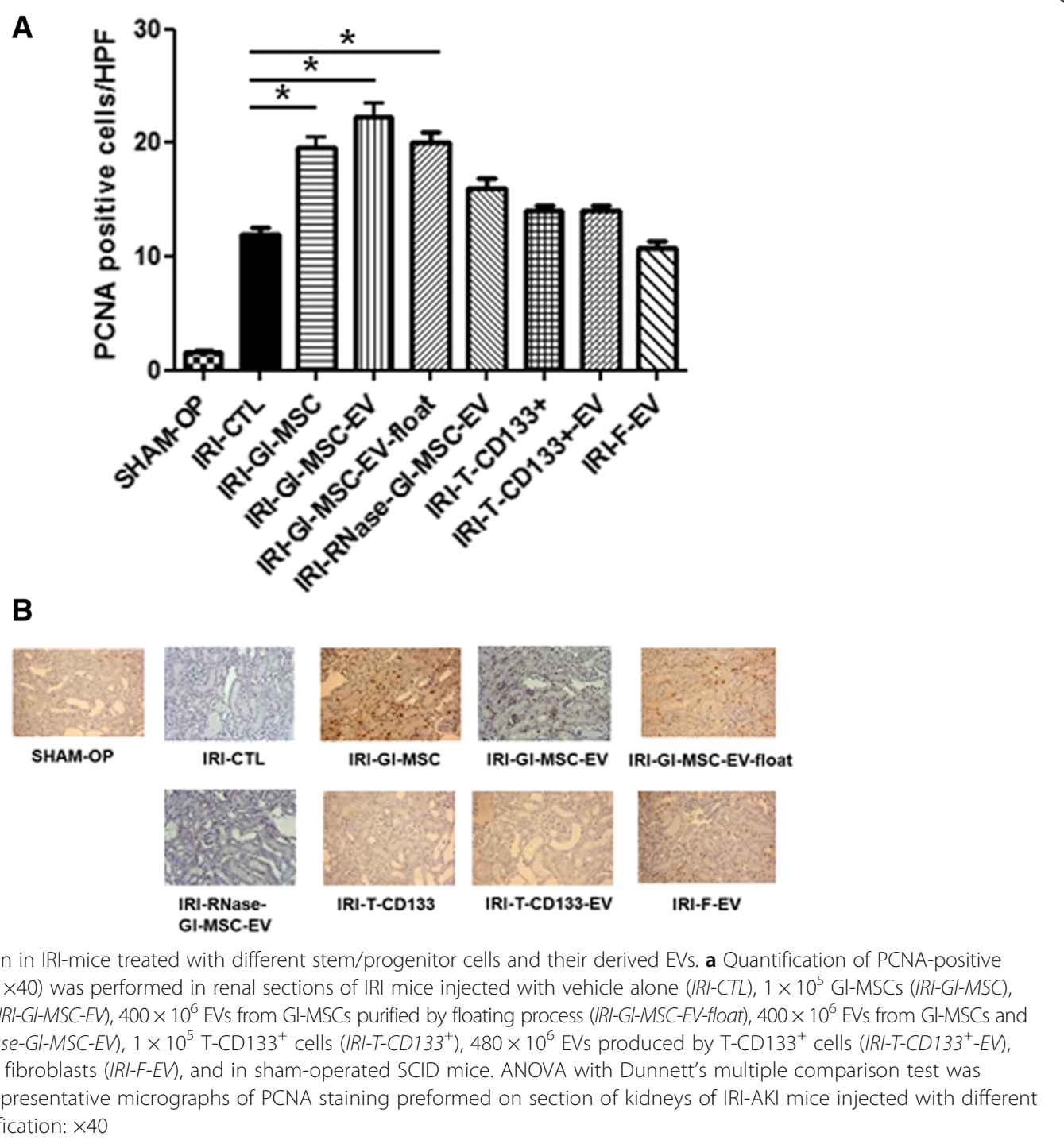

CD133 ${ }^{+}$-EVs were also positive for SSEA4, CD29 and CD146 (Fig. 4b). Nanosight analysis confirmed the average size of EVs derived from Gl-MSCs to be $170 \mathrm{~nm}$ with a mode of $131 \mathrm{~nm}$ and a standard deviation of $62 \mathrm{~nm}$ (Fig. 4c). Furthermore, EVs from T-CD $133^{+}$had an average size of $167 \mathrm{~nm}$, a mode of $129 \mathrm{~nm}$ and a standard deviation of $63 \mathrm{~nm}$ (Fig. 4d).

EVs derived from GI-MSCs protect against IRI-induced AKI To evaluate whether EVs derived from Gl-MSCs and $\mathrm{T}-\mathrm{CD} 133^{+}$cells were protective against AKI induced by IRI, EVs were injected in mice through the tail vein immediately after surgery. Blood chemistry analysis showed that the serum creatinine and BUN levels were significantly reduced in IRI animals treated with Gl-MSC-EVs compared to ones treated with T-CD $133^{+}$-EVs or with the vehicle alone (Fig. 1).
No significant differences were observed between treatment with Gl-MSC-EVs and Gl-MSCs (Figs. 1 and 2). The treatment of IRI mice with EVs derived from human fibroblasts had no protective effect whatsoever on AKI suggesting the specific therapeutic role of EVs derived from Gl-MSCs (Figs. 1 and 2). Futhermore, on comparing IRI mice treated with Gl-MSCEVs to IRI mice treated with vehicle alone showed that there was a marked increase in tubular proliferation in the former compared to the latter as quantified by PCNA (Fig. 3) and BrdU staining (Additional file 1: Figure S1).

Moreover, we observed an improvement in renal function, morphology and tubular proliferation using GlMSC-EVs obtained by floating to exclude contamination of non-vesicular RNA and proteins comparable to that obtained with Gl-MSC-EVs (Figs. 1, 2 and 3 and 

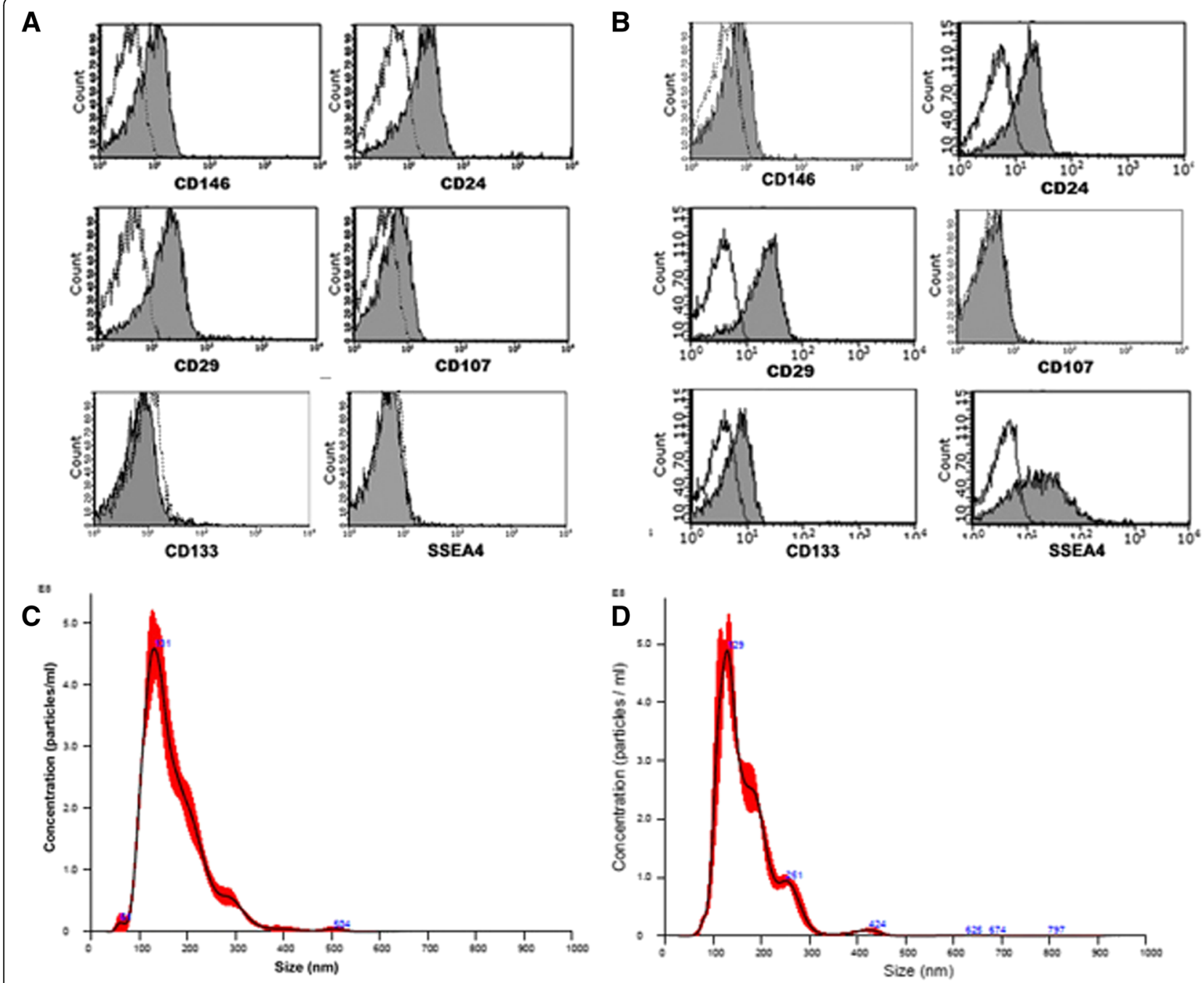

Fig. 4 Characterization of EV surface markers and size. Representative FACS analyses of the expression of specific mesenchymal stromal cell and renal progenitor cell markers by GI-MSC-EVs (a) and T-CD133+-EVs (b). White-filled histograms indicate the isotypic controls. c-d NTA analysis of GI-MSC-EVs (c) and of T-CD133+-EVs (d). Four different preparations were tested with similar results

Additional file 1: Figure S1). Whereas RNA in floating EVs was not reduced by physiological doses of RNase (see "Methods"), $5 \mu \mathrm{g} / \mathrm{ml}$ RNase was found to degrade vesicle-associated RNA as seen by bioanalyzer profiling (Fig. 5). Furthermore, RNase-treated EVs were ineffective in improving both kidney function and histological IRI recovery (Figs. 1, 2 and 3). Altogether, these results suggest that vesicular RNA was responsible for the beneficial effect of EVs in IRI mice.

\section{Bio-distribution of EVs in IRI-AKI mice}

Subsequently, the bio-distribution of EVs was checked by confocal microscopy at different time points (1, 6 and 24 hours) after injecting PKH26-labelled EVs in IRI mice. Interestingly, the labelled Gl-MSC-EVs could be detected in the kidneys of IRI mice as early as 1 hour after injection and subsequently 6 hours later especially in the tubules (Fig. 6b, c). However, 24 hours after administration only few EVs could be observed in the tubules of IRI mice (Fig. 6d). No significant accumulation of EVs was detected in the kidney of sham-operated mice (Fig. 6a). The biodistribution observed in mice treated with Gl-MSCEVs was also seen in mice treated with T-CD133 ${ }^{+}$-EVs with a maximum detection of EVs in the tubules 1 hour after injection; however, this decreased at 6 hours and 24 hours subsequently (Fig. 6e-g). Although a slight amount of fibroblast-EVs were detected in the tubules 1 hour after injection, they failed to accumulate compared to the Gl-MSC-EVs and T-CD133 ${ }^{+}$-EVs (Fig. $6 \mathrm{~h}-\mathrm{l}$ ). A significant buildup of Gl-MSC-EVs, TCD133 ${ }^{+}$-EVs and fibroblast-EVs was observed in the liver 

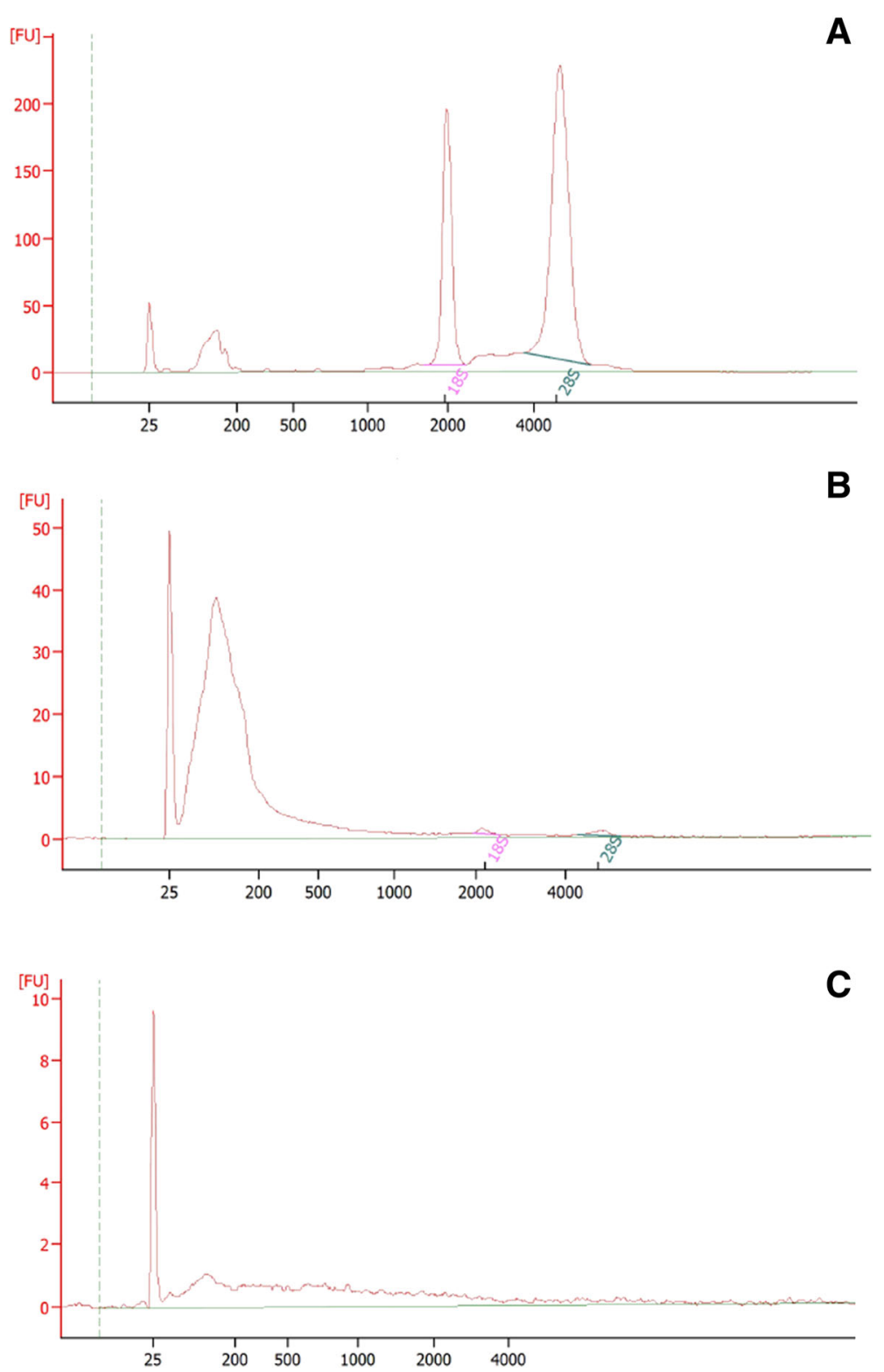

Fig. 5 Characterization of EV RNA content. Representative bioanalyzer profiles, showing the size distribution of total RNA extracted from GI-MSCS and GI-MSC-EVs. The first peak (left side of each panel) represents an internal standard. The two peaks of ribosomal RNA 185 and 285 are detectable in cells (a) and barely detectable in the corresponding EVs (b). EVs exhibited a relevant peak of small RNAs. After treatment with RNase A (c), RNAs inside EVs were degraded

of IRI mice both at 1 and 6 hours, respectively (Fig. 7b-c, e-f, h-i) and the same in sham-operated mice as well (Fig. 7a). No EVs were detected in the liver after 24 hours post administration (Fig. 6d, g, l).

\section{MicroRNA profiling in GI-MSC-EVs and comparative pathway analyses}

By performing a TaqMan ${ }^{\mathrm{Tu}}$ array miRNA analysis we identified 62 miRNAs (Table 3) that were specifically expressed in Gl-MSC-EVs $(\mathrm{Ct}<35)$ and not in fibroblastEVs $(\mathrm{Ct}>35)$. A target prediction analysis was performed using the Funrich tool software which identified 7318 gene targets by the selected miRNAs. The biological processes over-represented by the predicted targeted genes of miRNAs from Gl-MSC-EVs were related to nucleic acid metabolism, transport, cell communication, regulation of cell growth and gene expression $(p<0.05)$ (Fig. 8).

\section{Discussion}

In this study, we found that Gl-MSCs injected intravenously soon after kidney revascularization contributed towards reducing ischemic damage in an experimental 
A

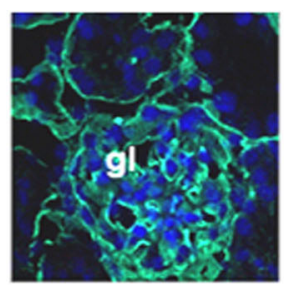

B

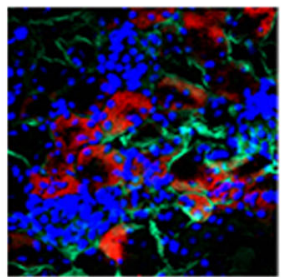

E

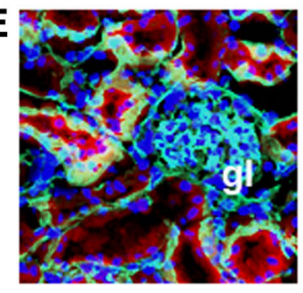

$\mathrm{H}$

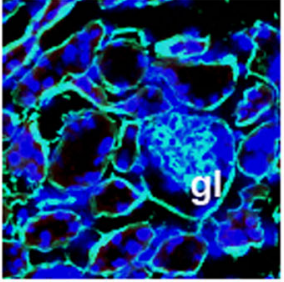

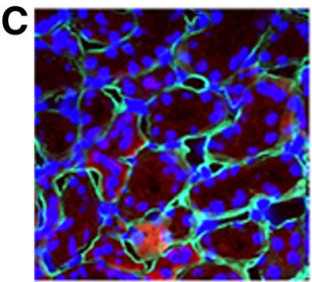
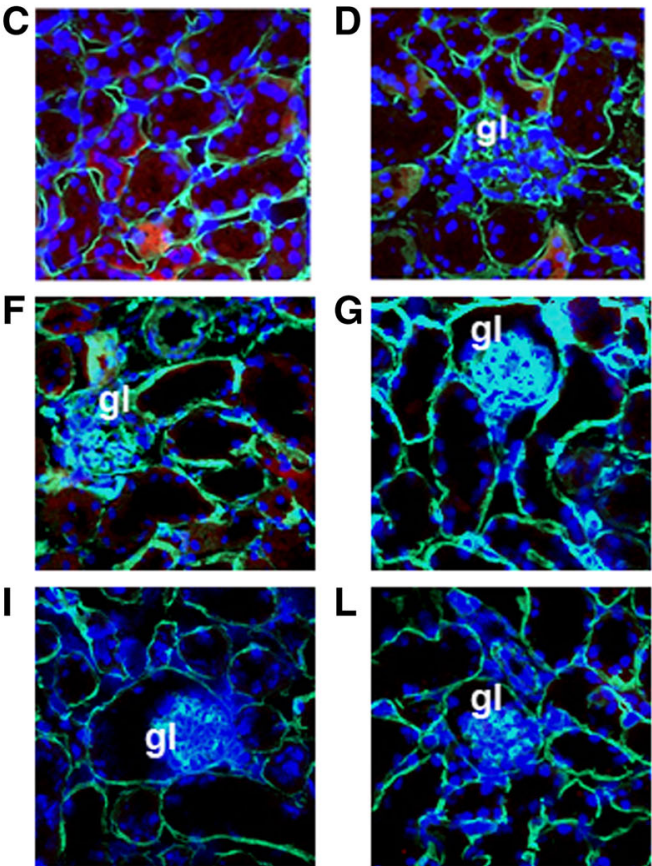

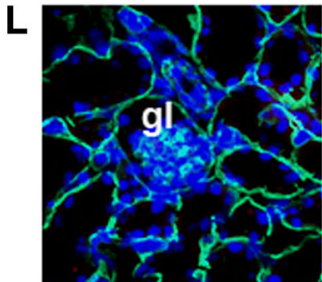

Fig. 6 Distribution of EVs in the kidney after in vivo injection. Representative micrographs of kidney frozen tissue sections of mice injected with PKH26-labelled EVs (red) and stained with laminin antibody (green). Nuclei were stained in blue with Hoechst. a Distribution of GI-MSC-EVs, T-CD133+-EVs and fibroblast-EVs in sham-operated mice. The distribution of GI-MSC-EVs in tubules of IRI mice at 1 (b), 6 (c) and 24 (d) hours after administration. The distribution of T-CD133+-EVs in tubules of IRI mice at $1(\mathbf{e}), 6(\mathbf{f})$ and $24(\mathbf{g})$ hours after administration. The distribution of fibroblast-EVs in tubules of IRI mice at 1 (h), 6 (i) and 24 (I) hours after administration. Original magnification: $\times 40$, except (a) $\times 63$

model of IRI-induced AKI. This effect was mimicked by EVs released from Gl-MSCs suggesting their involvement in a paracrine fashion towards the beneficial effects on renal ischemic damage induced by IRI. In contrast, both $\mathrm{CD} 133^{+}$renal progenitor cells isolated from the tubules and their subsequent EVs did not exhibit the same protective potential on IRI-induced AKI.

The presence of MSCs in the glomeruli has been shown in both rodents and humans [43, 44]. Gl-MSCs isolated from adult human-decapsulated glomeruli were positive for both mesenchymal stem cell markers (CD146, CD105, CD44, CD73, CD29) and renal stem cell markers such as: CD24 and PAX-2. Gl-MSCs were shown to be multipotent cells with the ability to differentiate into several mesenchymal cell types such as adipocytes, osteocytes, chondrocytes, as well as specific renal cells such as podocytes and mesangial cells [44]. Moreover, Gl-MSCs derived from cross-sex transplantation demonstrated the presence of genetic phenotype of the donor kidney, suggesting that the MSCs derived were from the resident population in the kidney rather than from the bone marrow of the recipient patient [44]. Consequently, MSCs isolated from renal murine tissues also express a specific pattern of renal genes not observed in MSCs of marrow origin, therefore possibly suggesting renal MSCs to have a memory of tissue origin [50].

Several studies have demonstrated the beneficial effects of renal resident and exogenous stem/progenitor cells in repairing kidney damage after toxic or ischemic AKI [9-12, 17, 23], however, no studies have been reported on the effects of renal resident MSCs. Interestingly, the process by which both exogenous and renal resident stem/progenitor cells exert their therapeutic effects have been attributed to paracrine mechanisms $[24,26,30,38,42]$. Numerous reports have indicated that there was a minimal incorporation of exogenous 

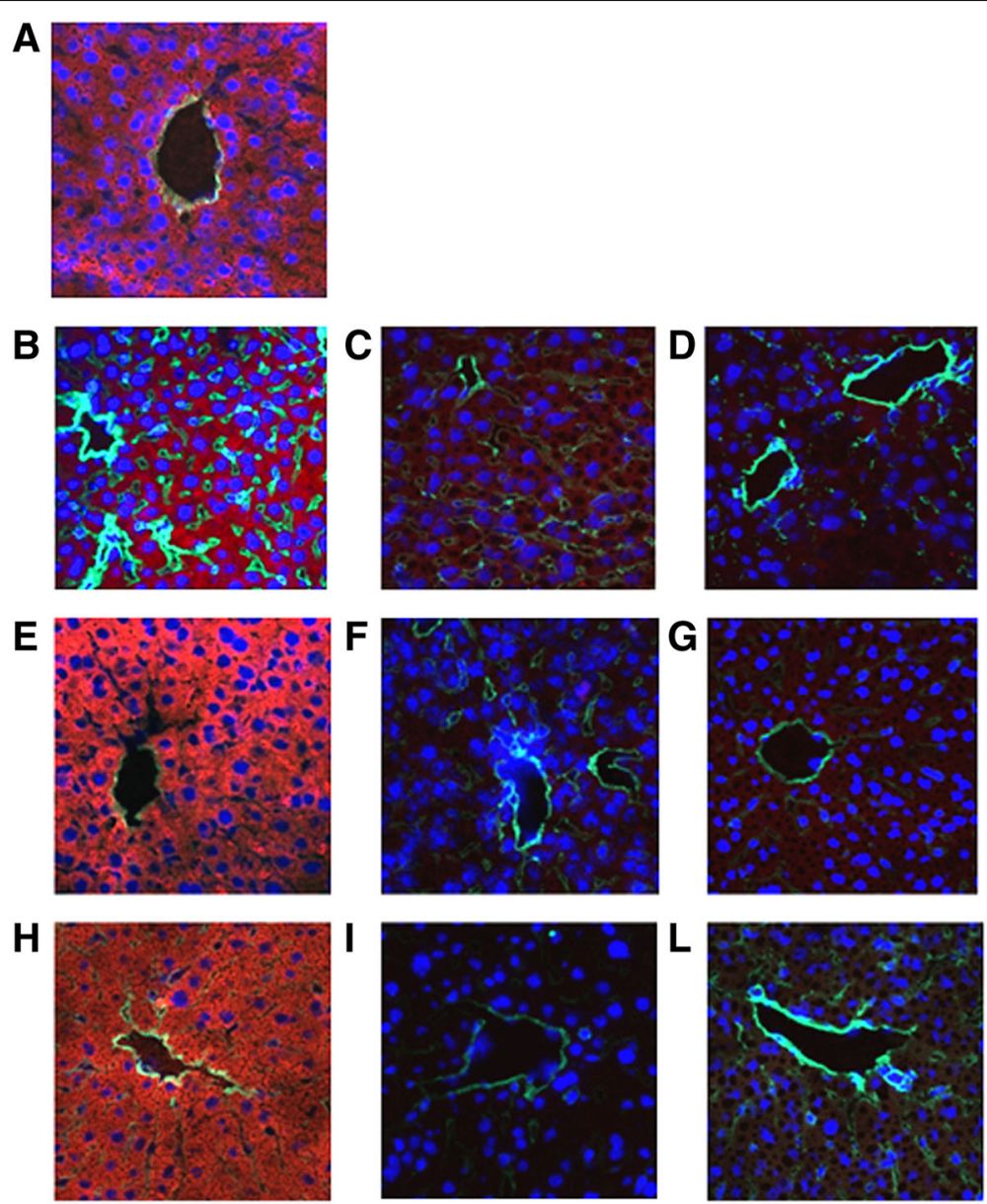

Fig. 7 The distribution of EVs in the liver after in vivo injection. Representative micrographs of liver frozen tissue sections of mice injected with PKH26labelled EVs (red) and stained with laminin antibody (green). Nuclei were stained in blue with Hoechst. a The distribution of GI-MSC-EVs, T-CD133+-EVs and fibroblast-EVs in sham-operated mice. The distribution of GI-MSC-EVs in the liver of IRI mice at 1 (b), 6 (c) and 24 (d) hours after administration. The distribution of T-CD133 ${ }^{+}$-EVs in the liver of IRI mice at 1 (e), 6 (f) and 24 (g) hours after administration. The distribution of fibroblast-EVs in the liver of IRI mice at 1 (h), 6 (i) and 24 (I) hours after administration. Original magnification: $\times 40$

bone marrow-derived MSCs in regenerating tubules after administration in AKI animal models [25]. Moreover, treatment with conditioned medium from MSCs was as effective as the cells. Several growth factors (VEGF [30] and IGF-1 [51]), cytokines and chemokines released by MSCs in the conditioned medium have been suggested to contribute towards this renoprotective effect $[24,29]$. EVs were also found to mediate the biological effects of MSCs in several experimental models [52-57], mainly by entering the target cells through specific receptors or by membrane fusion and transferring their biologically active contents such as proteins, mRNA and miRNA. This leads to the modification of the phenotype of recipient cells by either inducing activation of molecular pathways or epigenetic reprogramming [33, 36, 41, 46, 58, 59]. Recently, several authors including our group have demonstrated the protective role of EVs derived from different sources of MSCs not only in AKI $[38,39,60]$ but also in preventing the progression of AKI to CKD [61].

In the present model of IRI-induced AKI we report that $\mathrm{T}-\mathrm{CD} 133^{+}$cells and T-CD133 ${ }^{+}$-EVs were significantly less effective than Gl-MSCs and their subsequently derived EVs (GL-MSCs-EVs). Moreover, the specificity of Gl-MSCs-EVs was supported by the fact that EVs derived from fibroblasts were totally ineffective in the same setting. We also demonstrate that a single administration of Gl-MSCs during the reperfusion phase after renal ischemia significantly reduces kidney damage, stimulates renal tubular cell proliferation and leads to an improvement in overall kidney function. In addition, a similar beneficial effect was also observed when injecting a single dose of Gl-MSCs-EVs. However, on inactivating the RNA in the EVs reduced their protective effect 
Table 3 miRNAs specifically expressed by GI-MSC EVs and not by fibroblast EVs

\begin{tabular}{|c|c|}
\hline miRNA name & $\mathrm{RQ}$ \\
\hline hsa-miR-299-5p & 744029,35 \\
\hline hsa-miR-23a-3p & 26432,04 \\
\hline hsa-miR-302b-3p & 25250,07 \\
\hline hsa-miR-485-5p & 23058,32 \\
\hline hsa-let-7f-5p & 15771,15 \\
\hline hsa-miR-299-3p & 11417,82 \\
\hline hsa-miR-654-5p & 9548,11 \\
\hline hsa-miR-296-3p & 8522,14 \\
\hline hsa-miR-302a-3p & 5776,58 \\
\hline hsa-miR-139-3p & 4959,57 \\
\hline hsa-miR-200b-3p & 3600,55 \\
\hline hsa-miR-326 & 3468,27 \\
\hline hsa-miR-887-3p & 3189,25 \\
\hline hsa-miR-505-3p & 3017,21 \\
\hline hsa-miR-429 & 2670,70 \\
\hline hsa-miR-148b-3p & 2176,81 \\
\hline hsa-miR-122-5p & 2140,90 \\
\hline hsa-miR-449b-5p & 2069,40 \\
\hline hsa-miR-15a-5p & 1258,95 \\
\hline hsa-miR-215-5p & 1257,20 \\
\hline hsa-miR-135b-5p & 1162,49 \\
\hline hsa-miR-487a-3p & 1069,71 \\
\hline hsa-miR-338-3p & 1066,75 \\
\hline hsa-miR-409-5p & 1033,27 \\
\hline hsa-miR-367-3p, & 987,06 \\
\hline hsa-miR-23b-3p & 870,08 \\
\hline hsa-miR-490-3p & 674,18 \\
\hline hsa-miR-551b-3p & 634,73 \\
\hline hsa-miR-654-3p & 593,05 \\
\hline hsa-miR-147a & 573,64 \\
\hline hsa-miR-548d-5p & 480,04 \\
\hline hsa-miR-422a & 467,23 \\
\hline hsa-miR-597-5p & 410,72 \\
\hline hsa-miR-329-3p & 397,00 \\
\hline hsa-miR-330-5p & 353,61 \\
\hline hsa-miR-629-5p & 313,00 \\
\hline hsa-miR-589-5p & 247,28 \\
\hline hsa-miR-98-5p & 211,86 \\
\hline hsa-miR-375 & 209,38 \\
\hline hsa-miR-545-3p & 180,77 \\
\hline hsa-miR-146b-3p & 159,56 \\
\hline hsa-miR-542-3p & 139,68 \\
\hline hsa-miR-523-3p & 133,81 \\
\hline
\end{tabular}

Table 3 miRNAs specifically expressed by GI-MSC EVs and not by fibroblast EVs (Continued)

\begin{tabular}{ll}
\hline hsa-miR-518e-3p & 132,42 \\
hsa-miR-501-3p & 130,96 \\
hsa-miR-576-5p & 129,34 \\
hsa-miR-141-3p & 127,38 \\
hsa-miR-32-5p & 126,59 \\
hsa-miR-182-5p & 115,60 \\
hsa-miR-492 & 102,89 \\
hsa-miR-511-5p & 102,61 \\
hsa-miR-627-5p & 98,91 \\
hsa-miR-450b-5p & 68,40 \\
hsa-miR-517a-3p & 49,45 \\
hsa-miR-570-3p & 44,82 \\
hsa-miR-342-5p & 39,97 \\
hsa-miR-517c-3p & 38,64 \\
hsa-miR-522-3p & 33,08 \\
hsa-miR-330-3p & 22,93 \\
hsa-miR-576-3p & 19,88 \\
hsa-miR-449a & 13,55 \\
hsa-miR-369-5p & 11,64 \\
\hline
\end{tabular}

Cutoff setting: fibroblast EVs Ct $>35$; Gl-MSC EVs Ct $<35$

GI-MSC glomerular mesenchymal stromal cells, EVs extracellular vesicles

suggesting that the biological activity observed was partly associated with the RNA content carried by EVs.

To further investigate the relevance of specific RNA shuttled by Gl-MSC-EVs, we characterized the miRNA content of Gl-MSC-EVs comparing it with fibroblast EVs that were ineffective in this AKI model. What we found was that miRNAs specifically expressed and enriched in Gl-MSC-EVs have predicted target genes involved in various biological processes such as nucleic acid metabolism, transport, cell communication, regulation of cell growth and gene expression, which could potentially influence the pro-regenerative process triggered by GlMSC-EVs. Although the miRNA content of EVs from different stem cell populations play an important role in renal regeneration [62], we cannot exclude the possibility of other molecules shuttled by EVs (e.g. growth factors, cytokines and chemokines) or released by cells that may also be important contributors towards the proregenerative effects of Gl-MSC in IRI.

Cell therapy with stem progenitor cells including exogenous MSCs has been proven to be effective in kidney repair after toxic and ischemic induced-AKI, however, this mode of therapy has also been associated with severe side effects such as long-term mal- 


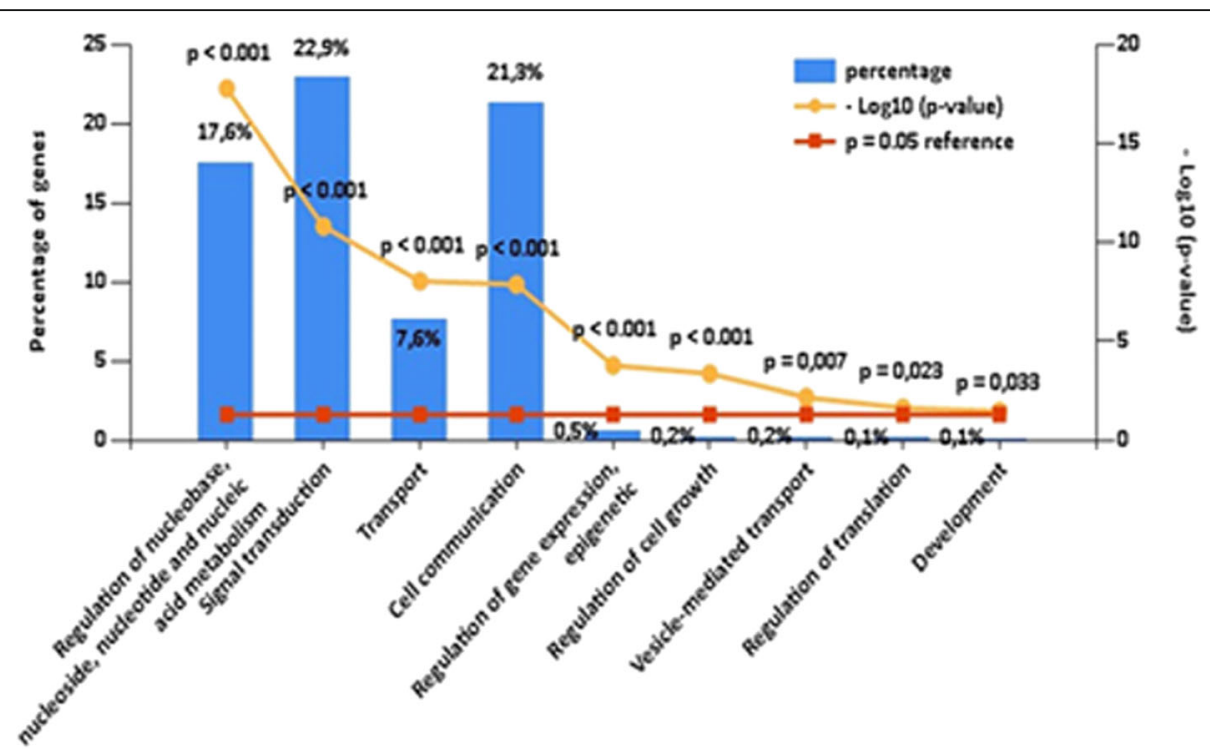

Fig. 8 The biological process analysis of predicted target genes of miRNAs enriched in GI-MSC-EVs. The bars represent the percentage of genes involved in that biological process; red line is the reference $p$ value; yellow line is the relative $p$ value for each category and is considered significant when $p<0.05$

differentiation of the engrafted cells [63] and the development of neoplastic lesions [64]. In addition, Tögel et al. reported that administration of bone marrow derived-MSCs in an experimental model of toxic AKI, could induce granulocytosis that worsens the intra-renal damage [65]. In addition, Burger et al. also demonstrated that injecting human umbilical cordderived progenitor $\mathrm{CD} 133^{+}$cells in ischemic inducedAKI unexpectedly exacerbated the kidney damage [66]. However, in our study we did not find any malignant lesions or mal-differentiation of the engrafted cells in the renal parenchyma 3 weeks after cell administration.

\section{Conclusions}

In conclusion, in this study we demonstrate for the first time that Gl-MSCs may contribute towards kidney repair after ischemic AKI. The mechanism can at least in part be ascribed to the release of EVs that are able to mimic the effect of Gl-MSCs.

\section{Additional file}

Additional file 1: Figure S1. Renal cell proliferation in IRI-mice treated with GI-MSCs-derived EVs. (A) Quantification of BrdU-positive cells/high power field (HPF) was performed in renal sections of IRI mice injected with vehicle alone (IRI-CTL), $400 \times 10^{6} \mathrm{EVs}$ produced by GI-MSCS (IRI-GIMSC-EV), $400 \times 10^{6}$ EVs produced by GI-MSCS and obtained by floating process (IRI-GI-MSC-EV-float), $400 \times 10^{6} \mathrm{EVs}$ produced by GI-MSCs and treated with RNase (IRI-RNase-GI-MSC-EV), and in sham-operated SCID mice. ANOVA with Dunnett's multiple comparison test was performed, ( $p<0.05$ ). (B) Representative micrographs of BrdU staining preformed on section of kidneys 2 days after IRI and treatments injection. Original magnification: $\times 40$. (DOCX $135 \mathrm{~kb})$

\section{Abbreviations}

AKI: Acute kidney injury; BUN: Blood urea nitrogen; CKD: Chronic kidney disease; EVs: Extracellular vesicles; GI-MSCs: Resident population of MSCS within glomeruli; IRI: Ischemia-reperfusion injury; MSCs: Mesenchymal stromal

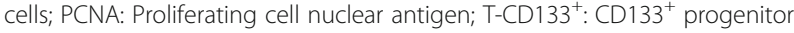
cells isolated from human tubules of the renal cortical tissue

\section{Acknowledgements}

The technical assistance of Federica Antico and Massimo Cedrino are gratefully acknowledged. We thank Sharad Kholia, a native English speaker, for the helpful revision of the manuscript.

\section{Funding}

Research grant from University of Torino (ex-60\% fund 2015) to AR.

\section{Availability of data and materials \\ Not applicable.}

\section{Authors' contributions}

AR carried out the in vivo experiments, analysed the data and wrote the manuscript. SB carried out the cell culture, isolation and characterization of cells and extracellular vesicles, analysed the data and edited the manuscript. BB analysed the data and edited the manuscript. AM carried out the cell culture, isolation and characterization of cells and extracellular vesicles. VD carried out isolation and analyses of RNAs. MT performed the array of miRNA content and bio-informatic analyses. LB analysed the data and edited the manuscript. PG collected tissue samples and edited the manuscript. BF collected tissue samples and edited the manuscript. GC conceived the study and critically revised the manuscript. All authors read and approved the final manuscript.

\section{Competing interests}

$\mathrm{SB}, \mathrm{BB}$ and $\mathrm{GC}$ are named inventors in related patents. The authors declare that they have no competing interests.

\section{Consent for publication}

Not applicable.

\section{Ethics approval}

Human tissues were obtained from cancer patients with informed consent in accordance with the Declaration of Helsinki and after approval by the Ethics 
Committee of the Azienda Ospedaliera Universitaria, Città della Salute e della Scienza, Torino (N. 168/2014).

All animal procedures were approved by the Ethics Committee of the University of Torino and conducted in accordance with the National Institute of Health Guide for the Care and Use of Laboratory Animals.

\section{Author details}

${ }^{1}$ Department of Medical Sciences and Molecular Biotechnology Center, University of Torino, Corso Dogliotti 14, Torino 10126, Italy. ${ }^{2}$ Department of Molecular Biotechnology and Health Sciences and Molecular Biotechnology Center, University of Torino, Torino, Italy. ${ }^{3}$ Department of Surgical Sciences, Città della Salute e della Scienza, University of Turin, Torino, Italy.

Received: 18 July 2016 Revised: 5 January 2017 Accepted: 10 January 2017 Published online: 07 February 2017

\section{References}

1. Munshi R, Hsu C, Himmelfarb J. Advances in understanding ischemic acute kidney injury. BMC Med. 2011;9:11.

2. Bianchi F, Sala E, Donadei C, Capelli I, La Manna G. Potential advantages of acute kidney injury management by mesenchymal stem cells. World J Stem Cells. 2014;6:644-50.

3. Lien YH, Lai LW, Silva AL. Pathogenesis of renal ischemia/reperfusion injury: lessons from knockout mice. Life Sci. 2003:74:543-52.

4. Duffield JS, Park KM, Hsiao LL, Kelley VR, Scadden DT, Ichimura T, et al. Restoration of tubular epithelial cells during repair of the postischemic kidney occurs independently of bone marrow-derived stem cells. J Clin Invest. 2005;115:1743-55.

5. Humphreys BD, Czerniak S, DiRocco DP, Hasnain W, Cheema R, Bonventre $J$. Repair of injured proximal tubule does not involve specialized progenitors. Proc Natl Acad Sci U S A. 2011;108:9226-31.

6. Berger K, Bangen JM, Hammerich L, Liedtke C, Floege J, Smeets B, et al. Origin of regenerating tubular cells after acute kidney injury. Proc Natl Acad Sci U S A. 2014;111:1533-8

7. Lin F, Moran A, Igarashi P. Intrarenal cells, not bone marrow-derived cells, are the major source for regeneration in postischemic kidney. J Clin Invest. 2005;115(7):1756-64

8. Sancho-Martínez SM, López-Novoa JM, López-Hernández FJ. Pathophysiological role of different tubular epithelial cell death modes in acute kidney injury. Clin Kidney J. 2015;8:48-59.

9. Bussolati B, Bruno S, Grange C, Buttiglieri S, Deregibus MC, Cantino D, et al. Isolation of renal progenitor cells from adult human kidney. Am J Pathol. 2005; 166:545-55.

10. Grange C, Moggio A, Tapparo M, Porta S, Camussi G, Bussolati B. Protective effect and localization by optical imaging of human renal CD133+ progenitor cells in an acute kidney injury model. Physiol Rep. 2014;2(5):e12009.

11. Sagrinati C, Netti GS, Mazzinghi B, Lazzeri E, Liotta F, Frosali F, et al. Isolation and characterization of multipotent progenitor cells from the Bowman's capsule of adult human kidneys. J Am Soc Nephrol. 2006;17(9):2443-56.

12. Angelotti ML, Ronconi E, Ballerini L, Peired A, Mazzinghi B, Sagrinati C, et al. Characterization of renal progenitors committed toward tubular lineage and their regenerative potential in renal tubular injury. Stem Cells. 2012;30(8):1714-25.

13. Langworthy M, Zhou B, de Caestecker M, Moeckel G, Baldwin HS. NFATC1 identifies a population of proximal tubule cell progenitors. J Am Soc Nephrol. 2009;20(2):311-21.

14. Lombardi D, Becherucci F, Romagnani P. How much can the tubule regenerate and who does it? An open question. Nephrol Dial Transplant. 2015;31(8):1243-50.

15. Ward HH, Romero E, Welford A, Pickett G, Bacallao R. Gattone 2nd VH, et al. Adult human CD133/1(+) kidney cells isolated from papilla integrate into developing kidney tubules. Biochim Biophys Acta. 2011;1812(10):1344-57.

16. Smeets B, Boor P, Dijkman H, Sharma SV, Jirak P, Mooren F, et al. Proximal tubular cells contain a phenotypically distinct, scattered cell population involved in tubular regeneration. J Pathol. 2013;229:645-59.

17. Lange C, Tögel F, Ittrich H, Clayton F, Nolte-Ernsting C, Zander AR, et al. Administered mesenchymal stem cells enhance recovery from ischemia/ reperfusion-induced acute renal failure in rats. Kidney Int. 2005;68:1613-7.

18. Morigi M, Imberti B, Zoja C, Corna D, Tomasoni S, Abbate M, et al. Mesenchymal stem cells are renotropic, helping to repair the kidney and improve function in acute renal failure. J Am Soc Nephrol. 2004;15:1794-804.
19. Zhuo W, Liao L, Fu Y, Xu T, Wu W, Yang S, et al. Efficiency of endovenous versus arterial administration of mesenchymal stem cells for ischemia-reperfusion-induced renal dysfunction in rats. Transplant Proc. 2013:45:503-10.

20. Lin F, Cordes K, Li L, Hood L, Couser WG, Shankland SJ, et al. Hematopoietic stem cells contribute to the regeneration of renal tubules after renal ischemia-reperfusion injury in mice. J Am Soc Nephrol. 2003;14:1188-99.

21. Tögel F, Yang Y, Zhang P, Hu Z, Westenfelder C. Bioluminescence imaging to monitor the in vivo distribution of administered mesenchymal stem cells in acute kidney injury. Am J Physiol Renal Physiol. 2008;295:F315-21.

22. Hauser PV, De Fazio R, Bruno S, Sdei S, Grange C, Bussolati B, et al. Stem cells derived from human amniotic fluid contribute to acute kidney injury recovery. Am J Pathol. 2010;177:2011-2.

23. Herrera MB, Bussolati B, Bruno S, Morando L, Mauriello-Romanazzi G, Sanavio F, et al. Exogenous mesenchymal stem cells localize to the kidney by means of CD44 following acute tubular injury. Kidney Int. 2007;72:430-41.

24. Tögel F, Hu Z, Weiss K, Isaac J, Lange C, Westenfelder C. Administered mesenchymal stem cells protect against ischemic acute renal failure through differentiation-independent mechanisms. Am J Physiol Renal Physiol. 2005:289:F31-42.

25. Rabb H. Paracrine and differentiation mechanisms underlying stem cell therapy for the damaged kidney. Am J Physiol Renal Physiol. 2005;289:F29-F30.

26. Tögel F, Weiss K, Yang Y, Hu Z, Zhang P, Westenfelder C. Vasculotropic, paracrine actions of infused mesenchymal stem cells are important to the recovery from acute kidney injury. Am J Physiol Renal Physiol. 2007;292:F1626-35.

27. Tang $Y L$, Zhao Q, Qin $X$, Shen $L$, Cheng $L$, Ge J, et al. Paracrine action enhances the effects of autologous mesenchymal stem cell transplantation on vascular regeneration in rat model of myocardial infarction. Ann Thorac Surg. 2005:80:229-36.

28. Majka M, Janowska-Wieczorek A, Ratajczak J, Ehrenman K, Pietrzkowski Z, Kowalska MA, et al. Numerous growth factors, cytokines, and chemokines are secreted by human CD34(+) cells, myeloblasts, erythroblasts, and megakaryoblasts and regulate normal hematopoiesis in an autocrine/ paracrine manner. Blood. 2001;97:3075-85.

29. Du T, Zou X, Cheng J, Wu S, Zhong L, Ju G, et al. Human Wharton's jellyderived mesenchymal stromal cells reduce renal fibrosis through induction of native and foreign hepatocyte growth factor synthesis in injured tubular epithelial cells. Stem Cell Res Ther. 2013;4(3):59.

30. Tögel F, Zhang P, Hu Z, Westenfelder C. VEGF is a mediator of the renoprotective effects of multipotent marrow stromal cells in acute kidney injury. J Cell Mol Med. 2009;13(8B):2109-14.

31. Park KM, Byun JY, Kramers C, Kim Jl, Huang PL, Bonventre JV. Inducible nitric-oxide synthase is an important contributor to prolonged protective effects of ischemic preconditioning in the mouse kidney. J Biol Chem. 2003;278:27256-66.

32. Bruno S, Camussi G. Role of mesenchymal stem cell-derived microvesicles in tissue repair. Pediatr Nephrol. 2013;28:2249-54.

33. Ratajczak J, Wysoczynski M, Hayek F, Janowska-Wieczorek A, Ratajczak MZ Membrane-derived microvesicles: important and underappreciated mediators of cell-to-cell communication. Leukemia. 2006;20:1487-95.

34. Quesenberry PJ, Dooner MS, Aliotta JM. Stem cell plasticity revisited: the continuum marrow model and phenotypic changes mediated by microvesicles. Exp Hematol. 2010;8:581-92.

35. Camussi G, Deregibus MC, Bruno S, Cantaluppi V, Biancone L. Exosomes/ microvesicles as a mechanism of cell-to-cell communication. Kidney Int. 2010;78:838-48.

36. Valadi H, Ekström K, Bossios A, Sjöstrand M, Lee JJ, Lötvall JO. Exosomemediated transfer of mRNAs and microRNAs is a novel mechanism of genetic exchange between cells. Nat Cell Biol. 2007;9:654-9.

37. Mathivanan S, Ji H, Simpson RJ. Exosomes: extracellular organelles important in intercellular communication. J Proteomics. 2010;73(10):1907-20.

38. Bruno S, Grange C, Deregibus MC, Calogero RA, Saviozzi S, Collino F, et al. Mesenchymal stem cell-derived microvesicles protect against acute tubular injury. J Am Soc Nephrol. 2009;20:1053-67.

39. Zou X, Zhang G, Cheng Z, Yin D, Du T, Ju G, et al. Microvesicles derived from human Wharton's Jelly mesenchymal stromal cells ameliorate renal ischemia-reperfusion injury in rats by suppressing CX3CL1. Stem Cell Res Ther. 2014;5(2):40

40. Zhang G, Zou X, Miao S, Chen J, Du T, Zhong L, et al. The anti-oxidative role of micro-vesicles derived from human Wharton-Jelly mesenchymal stromal 
cells through NOX2/gp91(phox) suppression in alleviating renal ischemiareperfusion injury in rats. PLoS One. 2014;9(3):e92129.

41. Collino F, Deregibus MC, Bruno S, Sterpone L, Aghemo G, Viltono L, et al. Microvesicles derived from adult human bone marrow and tissue specific mesenchymal stem cells shuttle selected pattern of miRNAs. PLoS One. 2010;5(7):e11803.

42. Sallustio F, Costantino V, Cox SN, Loverre A, Divella C, Rizzi M, et al. Human renal stem/progenitor cells repair tubular epithelial cell injury through TLR2-driven inhibin-A and microvesicle-shuttled decorin. Kidney Int. 2013;83(3):392-403.

43. da Silva ML, Chagastelles PC, Nardi NB. Mesenchymal stem cells reside in virtually all post-natal organs and tissues. J Cell Sci. 2006;119:2204-13.

44. Bruno S, Bussolati B, Grange C, Collino F, di Cantogno LV, Herrera MB, et al. Isolation and characterization of resident mesenchymal stem cells in human glomeruli. Stem Cells Dev. 2009;8(6):867-80.

45. Lindoso RS, Collino F, Bruno S, Araujo DS, Sant'Anna JF, Tetta C, et al. Extracellular vesicles released from mesenchymal stromal cells modulate miRNA in renal tubular cells and inhibit ATP depletion injury. Stem Cells Dev. 2014;23(15):1809-19.

46. Colombo M, Raposo G, Thery C. Biogenesis, secretion and intercellular interactions of exosomes and other extracellular vesicles. Annu Rev Cell Dev Biol. 2014;30:255-89.

47. Kowal J, Arras G, Colombo M, Jouve M, Morath JP, Primdal-Bengtson B, et al. Proteomic comparison defines novel markers to characterize heterogeneous populations of extracellular vesicle subtypes. Proc Natl Acad Sci U S A. 2016; 113(8):E968-77.

48. Pathan M, Keerthikumar S, Ang CS, Gangoda L, Quek CY, Williamson NA, et al. An open access standalone functional enrichment and interaction network analysis tool. Proteomics. 2015;15(15):2597-601.

49. Morigi M, Introna M, Imberti B, Corna D, Abbate M, Rota C, et al. Human bone marrow mesenchymal stem cells accelerate recovery of acute renal injury and prolong survival in mice. Stem Cells. 2008;26:2075-82.

50. Pelekanos RA, Li J, Gongora M, Chandrakanthan V, Scown J, Suhaimi N, et al. Comprehensive transcriptome and immunophenotype analysis of renal and cardiac MSC-like populations supports strong congruence with bone marrow MSC despite maintenance of distinct identities. Stem Cell Res. 2012;8:58-73.

51. Imberti $B$, Morigi $M$, Tomasoni $S$, Rota C, Corna D, Longaretti L, et al. Insulin-like growth factor-1 sustains stem cell mediated renal repair. J Am Soc Nephrol. 2007;18(11):2921-8.

52. Doeppner TR, Herz J, Görgens A, Schlechter J, Ludwig AK, Radtke S, et al. Extracellular vesicles improve post-stroke neuroregeneration and prevent postischemic immunosuppression. Stem Cells Transl Med. 2015;4:1131-43.

53. Heldring N, Mäger I, Wood MJ, Le Blanc K, Andaloussi SE. Therapeutic potential of multipotent mesenchymal stromal cells and their extracellular vesicles. Hum Gene Ther. 2015;26:506-17.

54. Kilpinen L, Impola U, Sankkila L, Ritamo I, Aatonen M, Kilpinen S, et al. Extracellular membrane vesicles from umbilical cord blood-derived MSC protect against ischemic acute kidney injury, a feature that is lost after inflammatory conditioning. J Extracell Vesicles. 2013;10:2.

55. He J, Wang Y, Sun S, Yu M, Wang C, Pei X, et al. Bone marrow stem cellsderived microvesicles protect against renal injury in the mouse remnant kidney model. Nephrology (Carlton). 2012;7:493-500.

56. Nakamura Y, Miyaki S, Ishitobi H, Matsuyama S, Nakasa T, Kamei N, et al. Mesenchymal-stem-cell-derived exosomes accelerate skeletal muscle regeneration. FEBS Lett. 2015;589:1257-65.

57. Tan CY, Lai RC, Wong W, Dan YY, Lim SK, Ho HK. Mesenchymal stem cell-derived exosomes promote hepatic regeneration in drug-induced liver injury models. Stem Cell Res Ther. 2014;5(3):76.

58. Deregibus MC, Cantaluppi V, Calogero R, Lo lacono M, Tetta C, Biancone L, et al. Endothelial progenitor cell derived microvesicles activate an angiogenic program in endothelial cells by a horizontal transfer of mRNA. Blood. 2007:110:2440-8.

59. Cantaluppi V, Gatti S, Medica D, Figliolini F, Bruno S, Deregibus MC, et al. Microvesicles derived from endothelial progenitor cells protect the kidney from ischemia-reperfusion injury by microRNA-dependent reprogramming of resident renal cells. Kidney Int. 2012;82:412-27.

60. Bruno S, Grange C, Collino F, Deregibus MC, Cantaluppi V, Biancone L, et al. Microvesicles derived from mesenchymal stem cells enhance survival in a lethal model of acute kidney injury. PLoS One. 2012;7(3), e33115.

61. Gatti S, Bruno S, Deregibus MC, Sordi A, Cantaluppi V, Tetta C, et al. Microvesicles derived from human adult mesenchymal stem cells protect against ischaemia-reperfusion-induced acute and chronic kidney injury. Nephrol Dial Transplant. 2011;26(5):1474-83.

62. Collino F, Bruno S, Incarnato D, Dettori D, Neri F, Provero P, et al. AKI Recovery induced by mesenchymal stromal cell-derived extracellular vesicles carrying microRNAs. J Am Soc Nephrol. 2015;26:2349-60.

63. Kunter U, Rong S, Boor P, Eitner F, Müller-Newen G, Djuric Z, et al. Mesenchymal stem cells prevent progressive experimental renal failure but maldifferentiate into glomerular adipocytes. J Am Soc Nephrol. 2007;18(6):1754-64.

64. Thirabanjasak D, Tantiwongse K, Thorner PS. Angiomyeloproliferative lesions following autologous stem cell therapy. J Am Soc Nephrol. 2010;21(7):1218-22.

65. Tögel F, Isaac J, Westenfelder C. Hematopoietic stem cell mobilizationassociated granulocytosis severely worsens acute renal failure. J Am Soc Nephrol. 2004;15(5):1261-7.

66. Burger D, Gutsol A, Carter A, Allan DS, Touyz RM, Burns KD. Human cord blood CD133+ cells exacerbate ischemic acute kidney injury in mice. Nephrol Dial Transplant. 2012;27(10):3781-9.

\section{Submit your next manuscript to BioMed Central and we will help you at every step:}

- We accept pre-submission inquiries

- Our selector tool helps you to find the most relevant journal

- We provide round the clock customer support

- Convenient online submission

- Thorough peer review

- Inclusion in PubMed and all major indexing services

- Maximum visibility for your research

Submit your manuscript at www.biomedcentral.com/submit
() Biomed Central 